\title{
The Research Method of the Vegetation Cover Change effecting on Runoff
}

\author{
Yin Jianzhong \\ College of Civil Engineering, Tianjin University \\ Tianjin, China \\ yjzhfq@126.com
}

\author{
He Zhengwei \\ State Key Laboratory of Geohazard Prevention and \\ Geoenvironment Protection, Chengdu University of Technology \\ Chendu, China \\ hzw@cdut.edu.cn
}

\author{
He Fenqin \\ School of Environmental Science and Safety Engineering, Tianjin University of Technology \\ Tianjin, China \\ hfqyjz@126.com
}

\begin{abstract}
Researching the law of runoff has the important scientific and practical significance for the sustainable using and planning the water resources. Studying the relationship between changes of vegetation cover and runoff, it is important to regulate the water resources. Vegetation regulation of runoff is affected by vegetation type, age, spatial distribution of coverage. Application of remote sensing (RS) and geographic information system (GIS) analyzes the changes of vegetation cover in watershed, and using the gray relationship analysis researches the relevancy of vegetation change and the runoff, and discusses the laws and mechanisms of vegetation cover affecting the runoff.
\end{abstract}

Index Terms-Remote sensing (RS); Geographic information systems (GIS); Vegetation cover; Change; Runoff.

\section{INTRODUCTION}

Vegetation change, hydrological cycle and hydrological processes form a feedback control system of interact and influence each other, and it plays an important role in biogeochemical cycles. On the one hand, the existence of vegetation, growth, update, succession and distribution pattern changes influencing on the soil properties and microtopography, which affects runoff. On the other hand, runoff can change the soil properties and the micro-geographical environment, and reaction the vegetation growth, update, succession and vegetation distribution, which cause the vegetation changes (Wang Huaiyu, et al., 2010). The vegetation cover change is caused by natural and human factors. In recent years, with the increasing human factors (Liu Changming, et al., 2002), vegetation ecosystem services become increasingly weak, which caused water depletion, soil erosion, water pollution and even the frequent flooding and other issues appear. So people realize that the vegetation played an important role in maintaining water balance and coordination aspects of water demand conflicts (Qin Zhong, et al., 2001).
Researching the law of runoff has an important scientific and practical significance for the sustainable using and planning the water resources. Studying the relationship between changes of vegetation cover and runoff, it is important to regulate the water resources. Vegetation regulation of runoff is affected by vegetation type, age, spatial distribution of coverage. There is not conclusion about the impact of vegetation cover on runoff in the academic. There have three points of view. The vegetation increases the runoff. The vegetation and the runoff is not obvious relationship. The vegetation reduces the annual runoff.

\section{REVIEW}

\section{A. The Impact of Vegetation on Runoff}

The vegetation increases runoff. The runoff analysis for the Shitou and Heihe River basin in Qinling Mountains in northwest china, the result shows that the runoff of Heihe River decreased by $23.6 \%$ and $32.6 \%$ in 50 to 60 decade, because the quality of the watershed vegetation has been major damage. But the Shitou River basin have more forest land designated as protected areas, and forest quality has improved greatly, with an annual output per hectare flow $6405.9 \mathrm{~m}^{3}$, while in the Heihe River basin flow $4364.5 \mathrm{~m}^{3}$ per hectare, the former is $46.8 \%$ higher than the latter (Li Wenhua, et al., 2001). The results of comparative analysis in 5 groups of watershed $\left(674 \sim 5322 \mathrm{~km}^{2}\right)$ of china's Yangtze River also show that the annual runoff of more forest watershed basin than less forest, and the annual runoff coefficient increased $33 \%$ to $218 \%$ more forested watershed basin than less forested watershed (Li Wenhua, et al., 2001).

In the interpretation of this phenomenon, the researchers stressed the abundant forests in the humid climate of precipitation less evaporation conditions, good forest soil infiltration and water conservation role, thereby ensuring the 
uniformity of distribution of River water dry and flood flow regulation.

The presence of vegetation and the runoff is not obvious relationship. The observational data of Guaipo hydrological stations in Wanquan River and Maozhi hydrological station in Changhua River in Hainan Island show that the forest cover change with changes in river runoff is not very obvious, 60's, 70 's forest cover, respectively $15 \%, 40 \%$, annual precipitation respectively $2601,2428 \mathrm{~mm}$, average annual runoff were 1805 , 1676 mm (Li Wenhua, et al., 2001).

Liu Changming's analysis of rainfall and runoff of the Yellow River data(Liu Changming, et al., 1978), the results show that the annual runoff of the Loess Plateau vegetation is significantly lower than its outer edge, vegetation runoff coefficient is smaller than non- vegetation $40 \%$ to $60 \%$. The surrounding non-vegetation area is forest annual runoff 1.7-3.0 times.

\section{B. Methods and Means}

One method is laboratory simulation. The cycle of laboratory simulation is shorter and less interference factors, but it is hard on behalf of the actual situation of the field, and an indoor simulation results tend to be idealistic. So it is difficult to explain the field for the case of complex conditions, and still has many uncertainties.

Another method is field observation experiments. Early applying contrast basin or single basin through field observation experiments understand the effects of vegetation change on watershed hydrology. Field observations are usually carried out experiments using a combination of hydrologic methods, isotope hydrology methods and the dynamic hydrology methods, and effective integration of the slope scale and watershed scale, basin-scale studies to verify the scale of the slope, deeper understanding the process and mechanism of vegetation change effecting on runoff (Zhang Z.Q., et al., 2001). However, although the results of the experimental method of field observations can represent the complex conditions of the field situation, its cycle is longer. For example, the studies of the vegetation management measures on the impact of runoff, to update and restore vegetation cover often need ten years or even decades, and large capital investment and labor inputs, so experimentally observed field method has certain limitations.

The third method is hydrological model. The development of hydrological model is the inevitable result of the study of forest hydrology. The hydrological model develops from black-box model to the lumped model in initial, and eventually developed into a distributed hydrological model. Although a large number of existing water-soil erosion models based physical process for the various kinds scales, such as WEPP model, EUROSEM model, TOPMODEL, RHESSYS, SHE, the characterization of the model or the coupling of the vegetation is too simple, and rarely consider the feedback of the vegetation and hydrology process(Morgan R.P.C., et al., 1998; Mackay D.S., et al., 1997).

\section{QUESTION}

The impact of vegetation on runoff is extremely complex. The different geographical conditions or the different type and structures of the vegetation have different impact on the interception of precipitation, surface runoff, groundwater runoff and evaporation, so the space-time pattern and process are differences in a big cycle of water, small cycles of water and water balance. The research of the relationship between runoff and the vegetation type is more at home and abroad, but still not enough. Due to large differences in experimental conditions and the field natural conditions, the experimental results are quite different. The hydrological functions of vegetation need to be compared under different conditions, but the result of some environmental condition can not be applied as a general rule.

\section{DATA AND METHODS}

\section{A. Data Source}

Data used in the research include the topographic map of 1:10 million, TM / ETM remote sensing data(Fig.1), the vegetation type classification map of 1:25 million, and the basin's hydrological data.

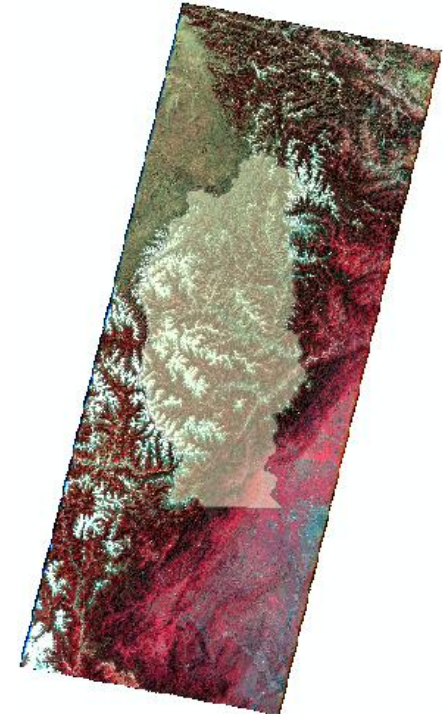

A. Mosaic of 3 scene by band 432

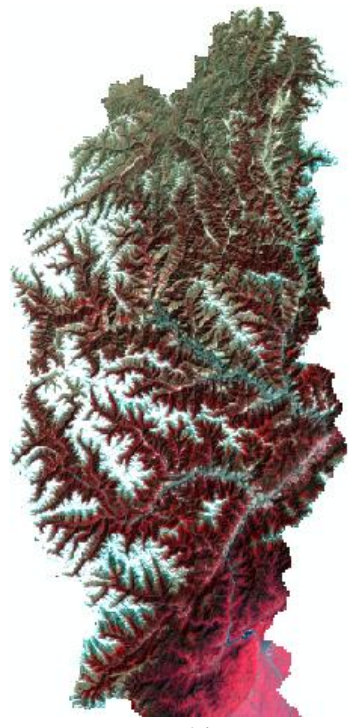

B. Researching area
Fig. 1. The remote sensing image of researching area

\section{B. Data Processing}

At present, researching the influence of vegetation on runoff mainly applies the two methods of basin parallel comparison and basin self comparison. In this paper, applying self-contrast method researches the influence of vegetation on runoff. Basin self comparison method mainly applies hydrological stations in the same valley and long-term field data, and analyzes the changes of the hydrological factors caused by the changes of watershed vegetation cover in different years, and researches the influence of vegetation change on watershed water balance and the water cycle. The core idea of this methodology is as Fig.2. 


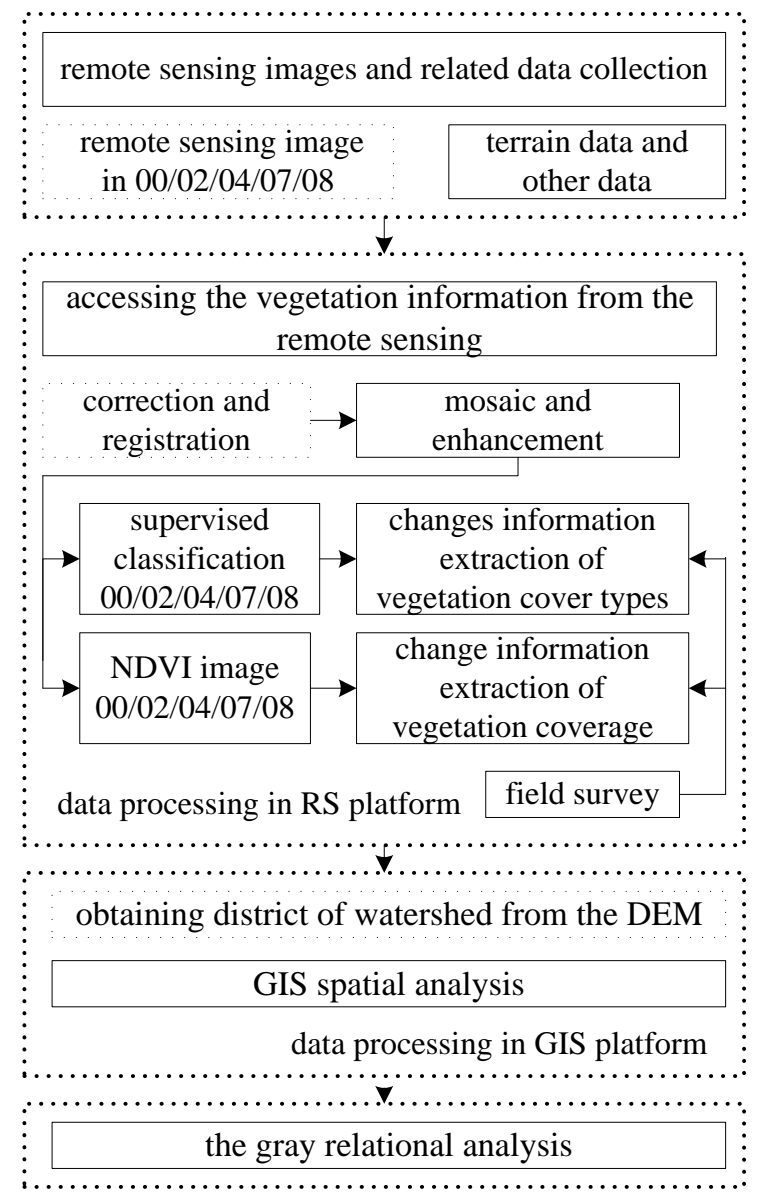

Fig. 2. Research methodology and technology

The First is obtaining district of watershed from the DEM. Obtaining digital terrain from vector topographic for the study area, making the DEM, the district information was achieved from the DEM for watershed.

The second is accessing the vegetation information from the remote sensing. The multi-stage remote sensing data was processed by geometric correction, band synthesis, enhancement, monitoring classification, changes found. So the change information of the study area was achieved, including vegetation type and vegetation index(Fig.3).

The third is GIS spatial analysis. Applying the GIS spatial analysis techniques analyzes the spatial changes of vegetation cover, and found the law of the spatial distribution of vegetation change in the study area.

The final is the gray relational analysis. Applying the grey relational analysis theory, analyzing the GIS analysis results of vegetation change and the measured data of hydrological basin, researches the associated extent of the vegetation change with the changes of basin runoff, and researches the laws and mechanisms of the vegetation cover affecting the runoff .

\section{CONCLUSION}

The current study, there are still many difficulties and the laws, mechanisms to be solved and explore, while still facing many challenging scientific problems, theories and methods must be resolved. The future will still need to be further advanced theories, methods, and the science and technology applied into research.
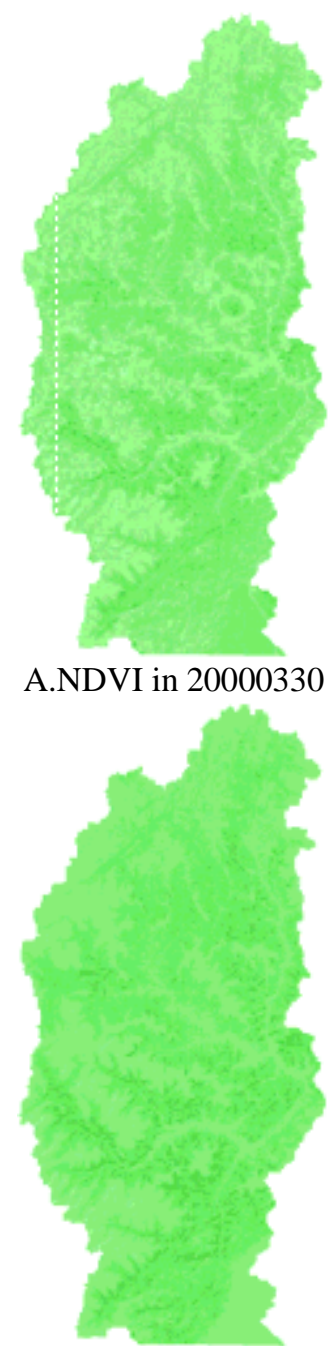

C. NDVI in 20040309

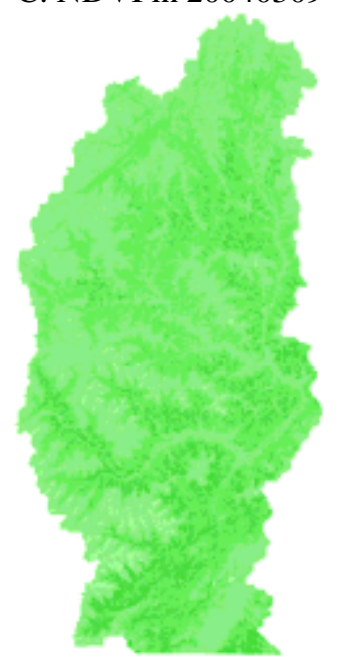

D. NDVI in 20070419

\section{Legend}

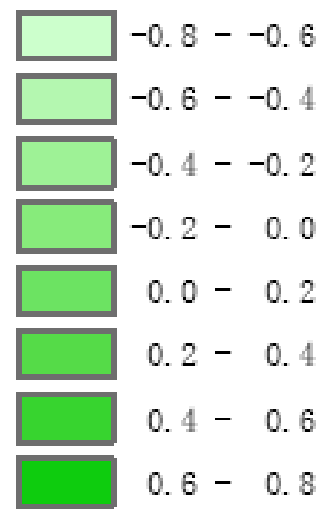

E. NDVI in 20080405

Fig. 3. NDVI of researching area in different time 
Strengthening the study of the principle and factors of the vegetation affecting the runoff, provide the theoretical basis for the researching of vegetation applying in water conservation, water purification. Strengthening the impact extent research of the vegetation on runoff, avoiding the hydrological effects to be exaggerated or reduced, so the results is closer to the actual law, can provide a reasonable basis for production practice.

\section{ACKNOWLEDGEMENTS}

This research was supported by the opening fund of state key laboratory of geohazard prevention and geoenvironment protection (Chengdu University of Technology) (SKLGP2011K005), and Tianjin higher school science and technology development fund projects (20100901).

\section{REFERENCE}

[1] Wang Huaiyu, Zhang Fuli, Huo Hong, "Research progress of the impact of forest vegetable change on river runoff in china," Forestry Science and Technology Information, vol. 42(1), pp. 8$11,2010$.

[2] Liu Changming, Zeng Yan, "Research on impact of vegetation change to water generation," China Water Resources, vol.(10), pp. 112-117, 2002.
[3] Qin Zhong, Zhou Zhaode, "Sustainable use of forests and water resources," Chinese Journal of Tropical Agriculture, vol. 91(3), pp. 49-55, 2001.

[4] Li Wenhua, He Yongtao, Yang Liyun, "A summary and perspective of forest vegetation impacts on water yield," Journal of Natural Resources, vol. 16(5), pp. 398-406, 2001.

[5] Liu Changming, Zhong Junxiang, "The influence of forest cover upon annual runoff in the loess plateau of china," Acta Geographica Sinica, vol. 33(2), pp. 112-127, 1978.

[6] Zhang Z.Q., Wang L.X., Yu X.X., "Impacts of forest vegetation on runoff generation mechanisms: a review," Journal of Natural Resources, vol. 16(1), pp. 79-84, 2001.

[7] Morgan R.P.C., Quinton J.N., Smith R.E., et al., "The european soil erosion model (EUROSEM): a process-based approach for predicting sediment transport from fields and small catchments," Earth Surface Processes and Landforms, vol. (23), pp. 527-544, 1998.

[8] Mackay D.S., Band L.E., "Forest ecosystem processes at the watershed scale: Dynamic coupling of distributed hydrology and canopy growth," Hydrological Processes, vol. (11), pp. 11971217, 1997. 